\title{
Manual Separation of Labial Adhesion in Pediatric Female Patients: A Five- year Experience
}

\author{
Khalid Mahmood, ${ }^{1}$ Zahid Mahmood Nagra, ${ }^{2}$ Muhammad Bilal Khalid ${ }^{3}$
}

1Department of Pediatric \& Neonatal Surgery, Punjab Medical College, FMU Faisalabad-Pakistan, 2Department of Plastic Surgery \& Burn unit, Punjab Medical College, FMU FaisalabadPakistan, ${ }^{33}$ rd year student of MBBS, CMH Lahore Medical College, Lahore-Pakistan

\section{ABSTRACT}

Background: Sinequia vulvae or fusion of labia minora is a benign condition in female babies. It is thin fusion of labia minora. The fusion may be due to chronic irritation of the vulva and poor hygiene. It results in bacterial infection, dysuria, post void dripping, urinary tract infection (UTI) and urinary tract obstruction. Different treatment options are available for this condition. Manual separation is the treatment of choice in our set up. Objective: To study the results of manual separation of labial adhesion under local or general anesthesia (GA), with two months follow up. Study Design: Observational study. Settings: Department of Paediatric Surgery, Allied Hospital, Faisalabad Medical University Faisalabad. Duration: July 2014 to June 2019. Methodology: All female neonates and infants presenting with labial fusion without other anomalies were included in this study. Cases with other associated anomalies such as anorectal anomalies were excluded from this study. Informed consent was obtained from their parents. Results: There were 273 cases with age ranging from 04 weeks to 5 year. All were female babies. Separation of adhesions was performed with 1 st follow up after 1 month. Twenty-six (9.52\%) patients were lost during follow up period. There were 223(91.20\%) patients had dissolved adhesions after $1^{\text {st }}$ follow up. Twenty-four (8.79\%) patients had recurrence and were re-operated. The success rate was $100 \%$ after $2^{\text {nd }}$ follow up after one month. Conclusion: Manual separation of labial adhesion is a procedure of choice in our society.

Keywords: Labial adhesion, Labial fusion, Manual separation, Sinequia vulvae.

Corresponding Author Submitted for Publication: 15-04-2020

Accepted for Publication: 08-06-2020

Dr. Khalid Mahmood, Associate Professor, Department of Pediatric \& Neonatal Surgery, Punjab Medical College, FMU Faisalabad-Pakistan. Email: khalid_ch@yahoo.com

Citation: Mahmood K, Nagra ZM, Khalid MB. Manual Separation of Labial Adhesion in Pediatric Female Patients: A Five-Year Experience. APMC 2020;14(2):119-21.

\section{DOI: 10.29054/APMC/2020.911}

\section{INTRODUCTION}

Fusion of the labia, labial adhesion, labial agglutination or sinequia vulvae in female babies is not an uncommon presentation in pediatric surgery. ${ }^{1}$ It is a benign gynecological problem presenting as partial or complete fusion of the labia minora or majora in the midline. ${ }^{2,3}$ The incidence of this anomaly is $1.8 \%$ with a peak at 13 to 23 months of age $(3.3 \%), 1,3,4,5$ These adhesions are sometimes attached with clitoris making it difficult to find an opening ${ }^{6}$. The vulva appears flat with central line of fusion. The urine dribbles posterior to clitoris. If adhesions are partial the central line of fusion would be visualized at posterior fourchette. ${ }^{7}$ The most frequently noted etiological factor is decrease in the estrogen needed for labial tissue strength in prepubertal period is no longer accepted now ${ }^{8}$. Other etiological factors include infection causing vulvovaginitis of labia minora, local trauma and irritation causing tissue damage and fibrinous exudate that leads to midline fusion of labia. Poor vulvar hygiene and history of sexual assault are also included in etiological factors. Local inflammation due to bacterial infection, threadworm infestation or a topical dermatitis may lead to labial adhesion.3,5,7,9 Labial adhesions may be mild, moderate and severe. Excessive use of soaps, foam baths, hip baths or other irritant substances, and even tight fitted cloths can be the triggering cause. Lichen sclerosis must be considered in the differential diagnosis. ${ }^{10,11}$ The symptoms depend on the extent of labial adhesions. A complete fusion may result in incontinence (dribbling). ${ }^{12}$ In some cases association with urinary tract infection (UTI)\& urinary tract obstruction were noted. 2,13,14,15 The proposed lines of treatment include observation, periodic follow up, topical treatment, manual and surgical separation. 1,4,8,9,16

\section{OBJECTIVE}

The objective of the study was to see the results of manual separation of labial adhesions under local or general anesthesia followed by topical antibacterial skin ointment application for three weeks, and white petroleum jelly for an additional one week.

\section{METHODOLOGY}

Study Design: Observational study.

Settings: The research was carried out in Paediatric Surgery Department Punjab Medical College (Allied Hospital), Faisalabad Medical University, Faisalabad. A retrospective review was done of the female patients who presented with fused labia to the Department of Pediatric \& Neonatal Surgery in Allied Hospital Faisalabad during the study period.

Duration: July 2014 to June 2019.

Sample Size: 273 female patients including in the study were aged 0 weeks to 5 years. 
Operational Definitions

Labial adhesion: Partial or complete fusion of the labia minora or majora in the midline.

Outcome: outcome is defined as initial successful treatment with totally resolved adhesion

Successful treatment: The complete resolution of adhesion with no recurrence after two months was registered as successful treatment.

Recurrence: It is defined as complete or partial recurrent adhesions.

Sampling Technique: Convenience sampling/Non probability consecutive sampling.

Sampling Selection

Inclusion criteria: All female neonates and infants presenting with labial fusion without other anomalies having symptoms of urinary obstruction, redness \&itching in the local area were included in this study. Informed consent was obtained from their parents.

Exclusion criteria: Cases with other associated anomalies in the anorectal and genitourinary tract were excluded from this study.

Record Review: Patients record that got manual separation was reviewed. Age at the time of first treatment, initial success and recurrence was noted. The patients with no adhesion after 2 months of initial treatment were labeled as successful treatment. The information regarding topical application after manual separation was also noted.

Procedure: Local anesthetic agent xylocain $5 \%$ was applied 45 minutes before the separation. In some patient's sedation with midazolam (Dormicum) $50-100 \mathrm{mcg} / \mathrm{kg}$ i/v 2-5 minutes before procedure along with local anesthesia was used ${ }^{4,10}$.

In general anesthesia, propofol and Sevoflurane gas was used 4 . Standing on right side of the patient wearing gloves, thumb of right hand was placed on left labia majora of the patient and the left thumb on the right labia majora. Then force was applied in lateral direction till normal anatomy of the vulva was visible. It would take 1-2 seconds for complete separation ${ }^{10}$.

Post operatively Polymixin B skin ointment $1 \mathrm{ml}$ was applied on the raw areas and vulva and the patients were advised to use it two times a day for three weeks. Then it was replaced with petroleum jelly $1-2 \mathrm{ml}$ twice daily application for further one week $^{4,6}$. Outcome was analysed after one month by the same surgical team. Then it was reanalyzed on second follow up i.e. two months after the procedure. If recurrence occurred after 1 sttreatment, then second procedure for separation was performed in the same way and results were noted. Parents were advised to keep good hygiene of the area constantly.

\section{RESULTS}

During the study period a total of 35,788 patients visited in pediatric Surgery out patient's department (OPD). Out of those patients $273(0.76 \%)$ presented with labial adhesions. The modes of presentation were, urinary tract infections and abnormal vulvar shape noted by mothers and grandmothers. Manual separation of 217 patients $(79.48 \%)$ with labial adhesions was performed at the outpatient clinic under sedation and local anesthesia. Fifty-six patients $(20.51 \%)$ underwent manual separation under general anesthesia. Twenty-six $(9.52 \%)$ patients were lost in follow up after initial treatment and were not included in analysis. There were $223(91.20 \%)$ patients who had resolved adhesions at first follow up (Table 1).

Table 1: Manual Separation of Labial Adhesions (After 1st \& $2^{\text {nd }}$ follow up)

\begin{tabular}{|l|l|}
\hline & N (\%) \\
\hline Total numbers of patients & 273 \\
\hline Initial successful treatment (after 1 month) & $223(91.20)$ \\
\hline Lost during 1st follow up & $26(9.52)$ \\
\hline Recurrence (after 1 month) & $24(8.79)$ \\
\hline Final success rate (after 2nd follow up) & $24(100)$ \\
\hline
\end{tabular}

Twenty-four $(8.79 \%)$ patients came with re-adhesions. So $2^{\text {nd }}$ manual separation procedure was performed. All patients came to outpatient department and were examined by the same team. The success rate after second procedure was $100 \%$. All the parents of the patients were advised to keep the area clean with soap and water.

Side effects: No local adverse effects of Polymyxin B skin ointment or white petroleum jelly were noted in the patients.

\section{DISCUSSION}

During the study period 35,788 patients visited pediatric surgery OPD. Out of those 273 patients were having labia adhesions. We performed manual separation procedure in all patients because of low socioeconomic and education level in our patients. They can't do medical treatment properly that would affect the results. The reported incidence of the disease by Barbosa ASD et al was $0.3-3.3 \%$ is comparable with our study $0.76 \% .{ }^{1}$ The peak age incident we found at the age of 12 months to 2 years $4 \%$ comparable with the study by Acer T et al was $3.3 \%{ }^{5}$ The initial success rate after separation of labial adhesions by Wejede $\mathrm{E}$ et al after one month of separation was $97 \%$ comparable with our study $91.20 \%$. The recurrence rate in the same study was $28 \%$ but our rate was $8.79 \%$ because small population $(n=30)$ of the study conducted by Wejde $E$ et al ${ }^{4}$. Our final Success rate was $100 \%$ after $2^{\text {nd }}$ labial separation but Wejde $\mathrm{E}$ declared $70 \%$ success in $2^{\text {nd }}$ separation. Previous studies of manual separation of labial adhesions by Sover T et al, Eroglu $\mathrm{E}$ et al and Schober $\mathrm{J}$ et al report the initial high success rate as in our study. ${ }^{17,18,19} \mathrm{~A}$ similar high success rate after $2^{\text {nd }}$ separation $100 \%$ in a small study group by Watanabe $T$ et al. Those patients received topical antibiotic postoperatively and cleanliness during follow up was ensured as in our study. 5,20 Barbosa ASD et al reported final success rate of $100 \%$ and recurrence of $10 \%$ comparable with our study i.e. final success rate of $100 \%$ and recurrence rate of $8.79 \%{ }^{1}$. In our study we noticed that the patients who had thick labial adhesions and needed general anesthesia had history of urinary tract infection. Melek $E$ et al noted the same thing in their study of labial 
adhesions. ${ }^{15}$ Bussen $S$ et al observed in their study an initial success rate of $100 \%$ after one month of separation, as compared with our study i.e. $91.20 \%$. After 2 months of follow up the success rate was $96 \%$ but in our study success rate was $100 \% .{ }^{10}$ The authors Watanabe et al \& Thibaud et al in their study of manual separation of labial adhesions observed significantly high success rate better than other treatment options..$^{20,21}$ Bussen $S$ et al came to conclusion in their study that the primary manual separation should be offered to solve the problem in single treatment sitting. ${ }^{10}$ The topical treatment failure can be due to lack of continuity of the treatment by the parents in our set up. Recurrence can be avoided with good hygiene of the area along with the use of antibiotic ointment for prolonged time. ${ }^{4,5}$

\section{CONCLUSION}

Manual separation is the procedure of choice in pediatric cases with labial adhesions in our set up. Recurrence can be avoided with prolonged use of ointment (Polymixin B) and good hygiene of the area.

\section{LIMITATIONS}

As this study is observational study, the education level of attendant of the patients is very low. It is not possible to suggest certain specialized precautions.

\section{SUGGESTIONS / RECOMMENDATIONS}

We suggest long follow up and multi central study. There is very few studies available in Pakistan so far. We recommend this observational study should be started in different Pediatric Surgery Units in Pakistan.

\section{CONFLICT OF INTEREST / DISCLOSURE}

There is no conflict of interest in this study. No funding was involved in this study.

\section{ACKNOWLEDGEMENTS}

We are thankful to the Prof. Dr. Sajid Hameed, Head of Department of Pediatric Surgery and Prof. Dr. Tanzeela Khalid for helping in identification of patients and research methodology.

\section{REFERENCES}

1. Barbosa ASD, Tristancho BAL, Suescun VJM. Labial adhesion: review of the literature. Arch Argent Pediatr 2017;115(6):597-601.

2. Bacon JL, Romano ME, Quint EH. Clinical Recommendation: Labial Adhesions. J Pediatr Adolesc Gynecol. 2015;28(5):405-9.

3. Silva D, Jayalath GKC, Ranweera AKP, Jayawardane M, et al. A new method of surgical treatment for recurrent labial adhesion in a prepubertal girl. Ceylon Medical Journal. 2012;57(4):168-9.

4. Wejde E. Ekmark AN. Stenstrom P. Treatment with estrogen or manual separation for labial adhesions- initial outcome and long term follow up. BMC Pediatr. 2018;18:104.

5. Acer T. Otgun I. Ozturk $O$ et al. Do hygienic factors affect labial fusion recurrence? A search for possible related etiologic factors. J Pediatr Surg. 2012;47(10):1913-8.
6. Samuels E. Ocheke AN, Nathaniel E et al.Labial adhesion in children at the Jos University Teaching Hospital. Afr. J Paediatric Surg. 2016;13(1):6-8.

7. Donna $E$, Wiener. Labial Adhesions. Pediatrics in Review.1994;15(3):87-8.

8. Moric BV, Lesar T. Treatment Modalities of Labial Fusion in Prepubertal Girls. Acta Med Croatica. 2014;68(4-5):389-92.

9. Mayoglou L, Dulabon L, Martin-Alguacil N et al. Success of treatment modalities for labial fusion: a retrospective evaluation of topical and surgical treatments. J Pediatr Adolesc Gynecol. 2008;22(4):247-50.

10. Bussen S. Eckert A. Schmidt U et al. Comparison of Conservative and Surgical Therapy Concepts for Synechia of the Labia in PrePubertal Girls. Geburtshilfe Frauenheilkd. 2016;76(4):390-5.

11. Vilano SE, Robbins CL. Common prepubertal vulvar conditions. Curr Opin Obstet Gynecol.2016;28(5):359-65.

12. Marc R. Laufer. Abnormalities of the Female Genital Tract. In:Corn A G, Adzick NS, Krummel TM et al.(editors).Pediatric Surgery 7th ed. Philadelphia: Mosby/ Elsevier. 2012 p.1606.

13. Janice L, Bacon. Clinical Recommendation: Labial Adhesions. J Pediatr Adolesc Gynecol. 2015;28(5):405-9.

14. Rubinstein A, Rehman G, Risso P, Ocampo D. Labial adhesions: Experience in a children's hospital. Arch Argent Pediatr. 2018;116(1):65-8.

15. Melek E. Kilicbay F. Sarikas NG et al. Labial adhesion and urinary tract problem: The importance of genital examination. J Pediatric Urology. 2015;12(2):1-5.

16. Muram D. Treatment of prepubertal girls with labial adhesions. J Pediatr Adolesc Gynecol.1999;12(2):67-70.

17. Sover $T$. Topical estrogen therapy in labial adhesion in children therapeutic or prophylactic. J Pediatr Adolesc Gynecol. 2007;20(4):241-4.

18. Eroglu $\mathrm{E}$ et al. How should we treat prepubertal labial adhesion? Retrospective comparison of topical treatments: estrogen only, betamethasone only, and combination estrogen and betamethasone. J Pediatr Adolesc Gynecol. 2011;24(6):389-91.

19. Schober J, Dulabon L, Martin-Alguacil $n$ et al. Significance of topicl estrogen to labial fusion and vaginal introital integrity. J Pediatr Adolesc Gynecol. 2006;19(5):337-9.

20. Watanabe T, Matsubara $S$, Fujinaga $Y$ et al. Manual separation followed by local cleanliness for pediatric labial adhesion. $J$ Obstet Gynecol. 2010;36(3):667-70.

21. Thibaud E, Duflos $C$. Plaidoyer pour l'enfant: le traitement de la coalescence des petites lèvres est inutile. Arch Argent Pediatr.2003;10(5):465-6.

\section{AUTHORSHIP CONTRIBUTION}

$\begin{array}{ll}\text { Dr. Khalid Mahmood } & \text { Study Designing, Results \& Discussion } \\ \text { Dr. Zahid Mahmood Nagra } & \text { Literature Review, Data Analysis, } \\ & \text { Reference Writing } \\ \text { Dr. Muhammad Bilal Khalid } & \begin{array}{l}\text { Data Collection, Proof Reading, } \\ \text { Manuscript Writing \& Final, Formatting } \\ \text { of the Article }\end{array}\end{array}$

